\title{
Innovación tecnológica y financiación de prestaciones
}

\author{
Carlos Campillo-Artero \\ Universitat Pompeu Fabra \\ Laura Vallejo Torres \\ Universidad de Las Palmas de Gran Canaria \\ Néboa Zozaya González \\ Fundación Weber
}

\section{Resumen}

La aparición de numerosas y variadas nuevas tecnologías con novedosos mecanismos de acción bajo un patrón de innovación incremental demanda una reforma estructural profunda de la regulación de su autorización y financiación. Son muchos los países que emplean la evaluación económica como cuarta barrera en las decisiones de financiación sanitaria. En España, a pesar de su inclusión explícita en el ordenamiento jurídico, su papel sigue siendo bastante limitado. De la mano de los enfoques más basados en el valor están surgiendo instrumentos innovadores de financiación, como el pago por resultados o la fijación de precios por indicación.

Palabras clave: innovación, financiación, regulación, valor, coste-efectividad, medicamentos.

Clasificación JEL: D61, I10, I18.

\begin{abstract}
The arrival of numerous and diverse new technologies with innovative mechanisms of action under a pattern of incremental innovation demands a profound structural reform of the regulation of their authorization and financing. Many countries use economic evaluation as a fourth barrier in health financing decisions. In Spain, despite its explicit inclusion in the law, its role is still quite limited. Alongside with value-based approaches, innovative financing instruments are emerging, such as payment by results or price setting by indication.
\end{abstract}

Keywords: innovation, financing, regulation, value, cost-effectiveness, medication.

JEL classification: D61, I10, I18.

\section{Qué es innovación}

A pesar de la, aunque insatisfecha, perentoria necesidad de disponer de una definición consensuada de innovación a escala internacional, ninguna de las que ofrecen los documentos de referencia, como el Manual de Oslo, el de Frascati, de la Unión Europea, del NICE británico, ni las que se encuentran en numerosos artículos científicos publicados goza de consenso ni se ha convertido en la de referencia internacional. Suelen ser incompletas e imprecisas y, algunas, controvertidas, como, por ejemplo, la de innovación disruptiva. 
Por este motivo, a los efectos de este artículo, consideramos que es más pragmático hacer una aproximación intuitiva al concepto.

Por un lado, se encuentran las que podrían considerarse innovaciones francas, que no dejan lugar a dudas y son de gran magnitud: el primer automóvil, avión o submarino, la primera bombilla, el suero fisiológico, la penicilina o la «lectura» del ADN. Por otro, aquellas innovaciones de mucha menor magnitud, incrementales, algunas que incluso aportan innovación mínima, marginal y aparecen paulatina y lentamente, como los diferentes automóviles de un mismo modelo, o de avión, los nuevos tipos de bombillas (desde la primera hasta las led) o de prótesis de cadera. La magnitud y el alcance diferencial en varias esferas de estos tipos de innovaciones pueden utilizarse intuitivamente como barra de medida de la innovación que aporta cualquier nueva tecnología. Por razones de extensión, limitamos este artículo a los tratamientos con medicamentos y biológicos.

\section{Cuánto se innova}

En los modelos vigentes de $\mathrm{I}+\mathrm{D}+\mathrm{i}$ y de regulación de las nuevas tecnologías médicas (medicamentos, nuevas terapias no farmacológicas, aparatos y dispositivos, pruebas diagnósticas, procedimientos quirúrgicos, modelos de gestión y organización de servicios) se aprecian hechos importantes y comunes derivados de su estructura, funcionamiento y resultados que han de destacarse y se describen seguidamente.

En primer lugar, la impresionante magnitud de numerosas innovaciones en medicina en el siglo xx y de sus resultados en salud, como las del primer grupo enumeradas más arriba, ha dado paso a una innovación también real, pero lenta, paulatina, de mucha menor escala, con rendimientos decrecientes, como las marginales del segundo grupo citado al principio. Su valor (por ejemplo, terapéutico o diagnóstico) relativo o incremental, esto es, respecto al valor de las existentes, cuando menos en el último par de décadas, decrece (Campillo-Artero, 2015; Campillo-Artero, 2014; Hans-Georg Eichler et al. 2015; Hans-Georg Eichler et al., 2010; Lanthier et al., 2013).

De disponer exclusivamente de tratamientos farmacológicos con medicamentos que son moléculas con una estructura sencilla, muy pequeñas y con una sola indicación o muy pocas, como la aspirina (con una masa molecular de 180 daltons), se ha logrado pasar a la administración de medicamentos biológicos, obtenidos de seres vivos (bacterias, linfocitos humanos, cultivos de tejidos), con masas moleculares y una complejidad estructural y funcional crecientes y mucho mayores que las de los anteriores, como la insulina, la eritropoietina o los anticuerpos monoclonales (con masas moleculares de 5.808, 30.400 y 150.000 daltons, respectivamente), y algunos con varias indicaciones muy distintas entre sí.

Más aún, actualmente se están administrando, por citar otros ejemplos, citoquinas (proteínas que regulan el funcionamiento de las células), moléculas de síntesis 
pequeñas unidas a anticuerpos, que las dirigen específicamente a su lugar de acción, o linfocitos $\mathrm{T}$ del propio paciente que se han modificado ex vivo para que, al reintroducirlos en él, ataquen directa y específicamente a las células tumorales. También se avanza con la administración de anticuerpos con nuevos mecanismos de acción, como los de los llamados inhibidores de check point, y los avances en terapia génica son notables: las células de los pacientes con diferentes enfermedades causadas por deficiencias de proteínas u hormonas también se modifican genéticamente infectándolas ex vivo con virus (denominados oncolíticos) que les transfieren el material genético que contiene la información para sintetizarlas. Al administrarles sus propias células así modificadas, producen las proteínas u hormonas, que suplen esas deficiencias.

Como se comentará más adelante por las ventajas y, sobre todo, por ciertos desafíos que plantea, otro avance lo constituye el paso de tratamientos secuenciales (un medicamento tras otro) de una enfermedad con varios medicamentos de síntesis y biológicos a su administración combinada, simultánea, así como la ampliación de indicaciones de un mismo tratamiento a diferentes enfermedades que se consiguen con las opciones terapéuticas señaladas en los párrafos anteriores. Algunos tumores diferentes en distintas localizaciones comparten las mismas dianas terapéuticas (por ejemplo, una mutación) a las cuales puede dirigirse la misma terapia (agnostic therapy). Por otro lado, la misma enfermedad puede tratarse simultáneamente con medicamentos diferentes, cada uno con su propio mecanismo de acción, que actúan en distintas vías metabólicas; de este modo se intenta reducir la posibilidad de que las células de un tumor muten y «escapen» a la acción de un medicamento que actúa en una vía metabólica utilizando otra vía metabólica alternativa (Bach, Giralt, y Saltz, 2017; Campillo-Artero, 2016; Dolgin, 2015; EMA - European Medicines Agency, 2016; Hunter y Sherman, 2017; Komarova y Boland, 2013; Kuehn, 2017; Lemery, Keegan y Pazdur, 2017; Li, Zhao y Wang, 2014; Miller y Lanthier, 2015; Neelapu et al., 2017; Prowell, Theoret y Pazdur, 2016; Rosenbaum, 2017; Schuster et al., 2017; Topalian, 2017; Tran, Longo y Urba, 2017; Webster, 2016).

Una cifra en aumento de reguladores, financiadores, agencias de evaluación y organizaciones y sociedades científicas de todo el mundo basan algunas de sus decisiones en el principio de que la magnitud de la innovación de una nueva tecnología médica viene o debería venir determinada en gran medida y en última instancia por su eficacia y seguridad relativas (frente a la mejor alternativa disponible) y no las absolutas (frente a placebo). Sobre la base de esta premisa, las valoraciones periódicas realizadas sobre la magnitud de la innovación de los nuevos medicamentos autorizados (como las de la FDA, de la revista Prescrire International, o las de la American Society of Clinical Oncology o la European Society of Clinical Oncology), algunas año tras año, ponen claramente de relieve y con gran congruencia entre ellas que su valor incremental es reducido. Así lo demuestran, por ejemplo, las ganancias estimadas de las medianas incrementales de supervivencia global o de progresión libre de enfermedad cifradas en días o en apenas más de dos meses que se consiguen con la mayoría de los nuevos tratamientos que aparecen en el mercado, 
salvo algunas excepciones. Los avances son muy notables en farmacodinámica (lo que el medicamento le hace al organismo) y farmacocinética (lo que el organismo hace con el medicamento), muy probablemente encierren gran potencial y sean muy promisorias, pero la magnitud innovadora de los avances y beneficios terapéuticos, de momento, es lenta y marginal (Arrowsmith, 2011; Borden y Dowlati, 2012; HansGeorg Eichler et al., 2015; Campillo-Artero, 2016; Campillo-Artero, 2014; HansGeorg Eichler et al., 2010; Hans-Georg Eichler et al., 2008; European Medicines Agency; Guo et al., 2010; Kimmelman, 2015; Lanthier et al., 2013; Papoian et al., 2015; Reeves, 2014; Van den Bogert y Cohen, 2015).

\section{Una instantánea de la regulación actual}

Las limitaciones, ineficiencias y externalidades negativas de los sistemas de $\mathrm{I}+\mathrm{D}+\mathrm{i}$ y regulatorios vigentes de muchos países -que se distribuyen entre las diferentes etapas de la $\mathrm{I}+\mathrm{D}+\mathrm{i}$ y de la regulación pre y posautorización- son otro hecho subrayable, porque explican algunas de las medidas que se han tomado y reformas que se han emprendido de dichos sistemas en los últimos años y ayuda a entender su situación actual.

\subsection{De la innovación a la autorización}

Cualquier intento de entender cabalmente la innovación en tecnologías médicas obliga a describir algunas premisas cruciales postuladas desde la ciencia regulatoria (regulatory science), aunque en este artículo se omiten los incentivos por razones de espacio (Institute of Medicine, 2011).

La primera premisa crucial es que una fracción importante de la ineficiencia y de los excesivos costes de la I+D+i de los medicamentos es atribuible a la elevada tasa de fracaso del desarrollo de los nuevos medicamentos: entre otras causas, casi el 50 por 100 de las nuevas moléculas no llegan al mercado por la incapacidad de demostrar la prueba del concepto (proof-of-concept) en fases I y II, por la obtención de resultados farmacodinámicos y farmacocinéticos insuficientes, por la progresión a fase III con resultados de fase II insuficientes, porque solo muestran beneficio marginal o equivalencia terapéutica, por la suposición errónea de que los mecanismos de acción y las dianas para una enfermedad son extrapolables a otras, o por el fallo en demostrar en ensayos pivotales de superioridad la eficacia y seguridad frente a placebo, a un nuevo tratamiento o a un control activo. Los pormenores de cada causa se encuentran en la bibliografía (Arrowsmith, 2011; Borden y Dowlati, 2012; Campillo-Artero, 2015; Campillo-Artero, 2013; Khozin et al., 2015; Kimmelman, 2015; Papoian et al., 2015; Putzeist et al., 2012; Reeves, 2014; Saini et al., 2014; Van den Bogert y Cohen, 2015; Woodcock, 2012; Yordanov et al., 2015; European Medicines Agency, 2014a). 
El coste creciente de la $\mathrm{I}+\mathrm{D}+\mathrm{i}$ con descenso de la innovación real, que se conoce como la paradoja de la innovación, es una de las consecuencias de estos hechos. Una entre tantas iniciativas puestas en marcha recientemente para intentar reducir algunas de estas limitaciones consiste en incorporar nuevos diseños de ensayos clínicos (basket, umbrella, empleados en medicina personalizada), incluidos los que eliminan las barreras entre las fases I, II y III (seamless drug development) (Institute of Medicine, 2013; Sleijfer, Bogaerts y Siu, 2013; Prowell, Theoret y Pazdur, 2016; Willyard, 2013; Janet Woodcock y LaVange, 2017).

La segunda premisa clave es que carecemos de un modelo regulatorio con criterios y estándares regulatorios congruentes para todos los tipos de tecnologías médicas. El examen de la regulación de su autorización revela la presencia de lo que se ha venido en llamar «escalera regulatoria». Con este concepto se intenta significar la existencia de un gradiente descendiente de regulación: los medicamentos se autorizan tras superar estándares de eficacia y seguridad severos, cuando menos de iure, aunque con limitaciones. En un escalón inferior, los estándares aplicados a los aparatos y dispositivos médicos de tipo III (aquellos de los que depende la vida de los pacientes y los que la pueden poner en peligro, como una prótesis valvular del corazón o un desfibrilador implantable) son menos severos o exigentes que los de los medicamentos y su cumplimiento es menor. Descendiendo otro escalón, hasta hace poco la autorización de las pruebas diagnósticas no se ha sometido a estándares regulatorios como los de los dos anteriores y los problemas de índole médica (daño a la salud) de su subregulación (underegulation) explican, tanto la profunda reforma que está llevando a cabo la FDA en los Estados Unidos (que afecta a los estándares de autorización, a los mecanismos destinados al cumplimiento de las normas regulatorias (law enforcement) y a la vigilancia postcomercialización), como la reforma aprobada en Europa, que no entrará en vigor hasta 2020 y 2022 por motivos que se analizan en otras publicaciones. En el último peldaño de la escalera se encuentran las innovaciones de las técnicas quirúrgicas, que no están reguladas, aunque se hayan propuesto modelos regulatorios y de evaluación postcomercialización (Breckenridge et al., 2011; Campillo-Artero, 2014).

La tercera premisa es que, desde su inicio, el modelo regulatorio de las tecnologías médicas se ha caracterizado por haber sido virtualmente binario: un nuevo medicamento o dispositivo médico se autoriza o no se autoriza. Pero en la última década y media, para reducir las profundas limitaciones, ineficiencias y externalidades negativas derivadas de un sistema regulatorio rígido, se están diseñando e implantando paulatinamente diversas alternativas de autorización, de cobertura y de fijación de precios más flexibles. Su pleno significado se resume en la aporía Evidence versus Access, que divide la vida de una tecnología en dos periodos (pre y postautorización), útiles para analizar escollos y soluciones propuestas y en curso, aunque en este artículo se evalúen casi a vuelapluma por razones de espacio (Baird et al., 2014; Barratt et al., 2012; Eichler et al., 2015; Eichler et al., 2012; European Medicines Agency, 2014a; European Medicines Agency, 2014b; European Medicines Agency, 2016; Goldman, Seigneuret y Eichler, 2015; Goldman, 2012; Husereau, Henshall y Jivraj, 2014; Massachusetts Institute of Technology, 2010). 
La cuarta y última premisa, muy vinculada con la anterior, es que las decisiones de autorización están expuestas a tres tipos de errores regulatorios relacionados con distintos grados de tolerancia a la incertidumbre que es consustancial a las decisiones de autorización: el conocido como tipo I (aprobar tempranamente una tecnología médica que a la postre resulta no ser eficaz o segura o que, siendo eficaz en cierta medida, su balance riesgo/beneficio es inadecuado); el de tipo II (retrasar su aprobación, aunque pueda demostrarse posteriormente que es eficaz y segura, privando así de su beneficio a los pacientes o retrasándolo); y el de tipo III (los costes de oportunidad asociados con los errores anteriores). La relación entre los beneficios y los distintos grados de tolerancia y aversión al riesgo, así como la mayor o menor incertidumbre de productores, reguladores, clínicos y pacientes sobre la efectividad y seguridad de las tecnologías tras haber sido autorizadas, junto con las decisiones que se toman en estas condiciones, conforman un conjunto de factores adicionales que también contribuyen a determinar la eficiencia económica del sistema regulatorio y, a la postre, los resultados en salud. Las reformas del aparato regulatorio pueden evaluarse considerando los costes de oportunidad y los costes y beneficios marginales de las medidas que se pretenden introducir. También pueden llevarse a cabo análisis del valor de la información, para ayudar a reducir dicha incertidumbre y aportar información útil en la toma de decisiones de autorización, pero apenas se consideran en la práctica (Bauer y König, 2014; Bouvy et al., 2013; Bouvy et al., 2012; Eckermann y Willan, 2007; Eichler et al., 2015; Eichler et al., 2013; Forda et al., 2013; McKenna y Claxton, 2011).

\subsection{La fase postautorización}

Los escollos que se intentan superar y desafíos que se afrontan hasta la autorización de medicamentos y las limitaciones de las etapas que la preceden tienen consecuencias directas e indirectas y se suman a los propios de la fase postautorización. Valga una breve enumeración de algunos importantes en aras de la brevedad: la variabilidad y el insuficiente grado de aplicación y cumplimiento de los estándares de eficacia y seguridad (más del segundo que del primero); la, asimismo, insuficiente aplicación de la eficacia y seguridad relativas y no de las absolutas como criterios (barreras) decisorios; el consiguiente impedimento (junto con otros) que ello supone para reducir la brecha entre eficacia y efectividad; la debilidad secular de los sistemas de regulación, vigilancia y control postcomercialización, aunados a las insuficiencias en calidad y cantidad de los estudios de efectividad comparada, para obtener información sobre efectividad y seguridad a fin de reducir la incertidumbre postautorización; los efectos de extensión y sustitución inadecuados, incluido el abuso del uso compasivo y fuera de ficha técnica; la disparidad entre los criterios de autorización, fijación de precios y reembolso entre reguladores, financiadores y agencias de evaluación de tecnologías sanitarias, que se verán en más detalle más adelante en este artículo; los empeños aún fallidos de armonizarlos, o la necesidad de evaluar más y mejor y mejorar el uso adecuado de los medicamentos (Campillo- 
Artero, 2014; Campillo-Artero, 2016; European Medicines Agency, 2014b; European Medicines Agency, 2014a; EMA - European Medicines Agency, 2016; Gaspar et al., 2012; Goldman, Seigneuret y Eichler, 2015; Goldman, 2012; Köhler et al., 2015; Messner et al., 2015; Messner y Tunis, 2012; Mestre-Ferrandiz et al., 2014; Moloney et al., 2015; Newton et al., 2015; Robinson, 2015; Towse y Garrison, 2013; Towse et al., 2015; Tsoi et al., 2013; Woodcock, 2012; Yordanov et al., 2015).

El avance en todas estas líneas de mejora trazadas exige, además, esfuerzos ímprobos de colaboración y coordinación entre todos los agentes y la mejora de la información de que disponen y comparten, porque sus necesidades de información y la naturaleza de las decisiones que tomas son diferentes, como traducen los modelos que desarrolla, por ejemplo, el MIT para mejorar las negociaciones entre ellos (Barratt et al., 2012; Backhouse et al., 2011; Gaspar et al., 2012; Köhler et al., 2015; Husereau, Henshall y Jivraj, 2014; Tsoi et al., 2013; Massachusetts Institute of Technology, 2010).

\section{Innovación en regulación: mejoras en marcha}

En las dos últimas décadas, en muchos países también se han ido introduciendo mejoras en todas las fases de la regulación (incluidos la I+D+i, el assessment, el appraisal y la monitorización tras la comercialización), que se han ido apuntando en los apartados anteriores y se recapitulan seguidamente a modo de síntesis:

- Promoción de la utilización de diseños experimentales y observacionales nuevos o infrautilizados más eficientes.

- Mejora de la información sobre seguridad en ensayos clínicos (estudios de farmacocinética, risk-benefit assessment o RBA, tolerability of risk thresholds, validación y calificación de biomarcadores, predicción de perfiles toxicológicos mediante modelos in silico, refuerzo de la farmacoepidemiología y Patient Reported Outcomes.

- Reforma de los criterios de regulación de pruebas diagnósticas, incluidos los biomarcadores de diagnóstico, pronóstico, respuesta y toxicidad (incorporación de la validez técnica, validez clínica, utilidad clínica), para mejorar su validez y rendimiento diagnósticos y, por ser imprescindibles, contribuir al avance de la medicina estratificada y personalizada, un punto que cobra mayor importancia a medida que aumenta el codesarrollo (co-development) de biomarcadores asociados a medicamentos.

- Revisión de los dinteles de incertidumbre, a fin de reducir los tres errores regulatorios asociados con las autorizaciones y sus consecuencias.

- Nuevos esquemas de autorización y acceso a nuevos medicamentos: revisión prioritaria (priority review), vía rápida de designación (fast track designation), acceso temprano (early access), aprobación acelerada (accelerated approval), revisión paralela (parallel review), aprobaciones condicionales (como la 
limitada a un subgrupo de pacientes y posteriormente ampliada con nuevas evidencias o staggered approval).

- Nuevos modelos de fijación de precios, como los basados en valor (value-based pricing), que se revisarán más adelante.

- Mayor y mejor aplicación de los distintos esquemas de cobertura y financiación, entre los que se encuentran los de reembolso condicionados (coverage with evidence development, patient access schemes) y los de riesgo compartido, que también se analizan en detalle más adelante.

- Mayor y mejor utilización de la evaluación económica como cuarta barrera y más transparencia, aspecto en el cual profundizaremos más adelante.

- Fomento de la efectividad comparada (comparative effectiveness), así como del big data, el real world data y el machine learning para aumentar y mejorar la información sobre efectividad y seguridad postcomercialización.

- Revisión y armonización progresiva de los criterios de autorización de nuevos medicamentos con los de fijación de precios y de reembolso con miras a reducir su heterogeneidad, sus incongruencias y la brecha entre necesidades de información de reguladores, financiadores y agencias de ETS.

- Introducción y pilotajes iniciales de las vías adaptativas (adaptive pathways), que se han explicado en profundidad en otras publicaciones.

A juzgar por las evaluaciones realizadas de estas medidas (menos de las necesarias), su grado de implantación es variable y las variaciones entre países son prominentes. Debe subrayarse, no obstante, que en conjunto deberían considerarse soluciones parciales y parcheadas de los problemas descritos.

Los modelos regulatorios actuales no gozan todavía de suficiente versatilidad para adaptarse de forma eficiente a los cambios de las características que muestra la innovación ni a las condiciones locales, ni han adoptado plena ni adecuadamente las medidas comentadas que se barajan para superar las limitaciones pre y posautorización y sus consecuencias.

Hay más consecuencias y más medidas, como, por ejemplo: la autorización de nuevos tratamientos medicamentosos y no medicamentosos a unos precios progresivamente más desorbitados respecto a su eficacia y seguridad relativas, al valor que aportan; las incongruencias y disparidades entre modelos de fijación de precios -algunos encaminados al precio basado en valor-y las formas como realmente se fijan, bastante desconocidas por falta de trasparencia, los desequilibrios de los excedentes de productores y consumidores y las pérdidas de bienestar social derivadas de ellos; o la fijación de precios de medicamentos con varias indicaciones, que se abordarán más adelante en este artículo. En suma, un ovillo de factores no exento de riesgos para la salud y que pone en solfa la capacidad de mejorarla y la eficiencia y sostenibilidad del sistema (Chandra, Garthwaite y Stern, 2017; Danzon, 2018; Mestre-Ferrandiz et al., 2018; Towse et al., 2013; Howard, 2011; Towse y Garrison, 2013; Towse et al., 2013; Towse, Cole y Zamora, 2018; van der Gronde, Uyl-de Groot y Pieters 2017). 
Desde hace años se están intensificando las demandas a escala internacional de acometer reformas estructurales profundas de los modelos de I+D+i y regulatorios actuales. Se han descrito aquí algunas reformas importantes, pero éstas son lentas, su grado de implantación varía entre países, y todavía son a todas luces insuficientes. La situación actual exige reformas sistémicas y más profundas en todas las aristas y facetas del sistema y con todos sus actores. Los costes sociales de la paresia regulatoria pueden ser elevadísimos.

\section{Financiación de la innovación: la cuarta barrera}

Tras hacer balance del estado actual de la innovación y del marco regulatorio existente y por desarrollar, en este apartado ahondaremos en los aspectos relativos a las decisiones de financiación de prestaciones sanitarias y en los criterios con las que estas se rigen.

La autorización de un nuevo medicamento debe superar tres barreras: demostrar su eficacia, seguridad y calidad. Sin embargo, la autorización de un medicamento no implica necesariamente su inclusión en el conjunto de prestaciones disponibles en la cartera de servicios de un sistema sanitario; especialmente si este es financiado con fondos públicos. Las agencias regulatorias y los financiadores de un número creciente de países emplean un criterio o barrera adicional para decidir sobre la cobertura pública de innovaciones sanitarias: el estudio de la eficiencia, o coste-efectividad.

La necesidad de este criterio se debe, en parte, al desequilibrio que caracteriza a los mercados sanitarios públicos que se enfrentan a una demanda ilimitada por parte de consumidores de servicios sanitarios que perciben un coste cercano o igual a cero en el momento de su uso y a una oferta limitada por las restricciones presupuestarias del sistema. Como resultado, los sistemas no pueden acceder a toda la innovación disponible y se requieren criterios de racionalización que nos alejen de la arbitrariedad y nos encaminen hacia la eficiencia. El objetivo no es ahorrar costes, sino distribuir los recursos existentes de forma que se alcance el mayor beneficio en salud posible para la población.

Por ello, al decidir si dar o no cobertura pública a un nuevo medicamento con un coste adicional para el sistema sanitario se deberá valorar a qué se está renunciando para poder financiar dicho medicamento. Esto es el coste de oportunidad de las decisiones de financiación sanitaria, es decir, las mejoras en salud que se perderán por no emplear esos recursos en su mejor uso alternativo. La Economía de la Salud proporciona una serie de herramientas para permitir incorporar el análisis de la eficiencia y la consideración del coste de oportunidad en la toma de decisiones. Entre estas herramientas destacan los análisis de coste-efectividad (ACE).

Los ACE se enmarcan en la llamada evaluación económica de tecnologías sanitarias, entendiendo tecnología en sentido amplio como señalábamos al inicio de este capítulo, incluyendo medicamentos, dispositivos, procedimientos diagnósticos o clínicos, modelos de gestión y organización de servicios. Una evaluación econó- 
mica no consiste únicamente en estimar los costes de un nuevo tratamiento. Para que un estudio sea considerado una evaluación económica, este debe cumplir con dos requisitos básicos: analizar tanto los costes como los resultados en salud asociados al nuevo tratamiento, y comparar estos con los que se obtienen con cursos alternativos de tratamiento (Drummond et al., 2015). El resultado del análisis se presenta en términos del coste incremental por unidad de efectividad en salud ganada de una tecnología frente a su comparador, empleando mayoritariamente los Años de Vida (AV) o los Años de Vida Ajustados por Calidad (AVAC) como medidas de efectividad. Se consideran coste-efectivas aquellas tecnologías cuyo coste por AV/AVAC esté por debajo de la cantidad establecida por el sistema como el máximo que se considera apropiado invertir por unidad de efectividad en salud. Esto es el llamado umbral de coste-efectividad, sobre el que profundizaremos más adelante.

Son muchos los países que incorporan el criterio de coste-efectividad en la toma de decisiones sobre inversión sanitaria, incluyendo Reino Unido, Australia, Canadá, Alemania, Suecia y Holanda, entre otros. En España, la posibilidad de contemplar la evaluación económica en la financiación de medicamentos se recoge desde la Ley del Medicamento de 1990, mención que se repite en sucesivas leyes del ordenamiento jurídico español. El Real Decreto-Ley (RDL) 16/2012 resaltó expresamente que las decisiones de financiación de medicamentos y productos sanitarios debían estar presididas por los criterios de evidencia científica de coste-efectividad y por la evaluación económica. En la práctica, sin embargo, el papel de la evaluación económica en la toma de decisiones en España es bastante limitado. El Tribunal de Cuentas, en su informe de fiscalización de la actividad económica en el área de farmacia del Ministerio de Sanidad, Servicios Sociales e Igualdad en los ejercicios 2014 y 2015 (Tribunal de Cuentas, 2016), expuso una serie de carencias claras: a fecha de la finalización del informe, el órgano asesor responsable de la aplicación del principio de coste-efectividad previsto en el RDL 16/2012 no había sido constituido y no existían manuales de procedimientos que recogiesen los criterios de evaluación establecidos para la inclusión de medicamentos en la prestación farmacéutica y en la fijación de precios. El Tribunal de Cuentas recomendó ampliar los estudios económicos que se realizan actualmente «por titulados farmacéuticos con amplia experiencia en el sector y con conocimientos en evaluación económica», y emplear procedimientos escritos y comunes para todos los evaluadores. Más demoledor fue el informe de 2015 de la Comisión Nacional de los Mercados y la Competencia (CNMC) al Proyecto de RD por el que se regula la financiación y fijación de precios de medicamentos y productos sanitarios (Comisión Nacional de los Mercados y la Competencia, 2015). Este desarrollo reglamentario no garantizaba, de acuerdo con la CNMC, la aplicación efectiva del principio de coste-efectividad, la transparencia, la independencia de criterio ni la capacitación técnica de los órganos decisores. El Proyecto de RD más reciente, publicado en 2018, por el que se regula el procedimiento de financiación de los productos sanitarios no apunta hacia una mejora de esta situación. En él se señala que «en caso necesario, el informe técnico de evaluación podrá incluir un análisis coste-efectividad», y que dicho «informe técnico de evaluación 
servirá de apoyo a la Comisión Interministerial de Precios de los Medicamentos». Por tanto, nos mantenemos en una situación en la que el estudio del coste-efectividad es opcional y los informes técnicos no tienen un carácter vinculante. Este contexto obstaculiza el empleo de estas herramientas, que dotarían a la toma de decisiones de una mayor transparencia y contribuirían a mejorar la solvencia y la sostenibilidad del sistema sanitario. Por terminar este apartado con un rayo de esperanza, hay que señalar que un entorno donde el papel, la rigurosidad y la transparencia de los estudios de coste-efectividad va en aumento es el de los informes elaborados por la Red de Agencias de Evaluación de Tecnologías Sanitarias y Prestaciones del SNS, pero cuyo alcance es muy insuficiente en la evaluación de medicamentos.

\section{El umbral de coste-efectividad}

Prometíamos profundizar sobre un concepto clave en la evaluación económica: el umbral de coste-efectividad. Y es que la información que proporcionan los ACE, en términos del coste incremental por unidad de efectividad en salud ganada de una tecnología frente a su comparador, no basta para emitir recomendaciones sobre si una tecnología debe o no ser financiada en un contexto determinado. Para ello se precisa comparar este coste incremental de la tecnología bajo estudio con un valor umbral que dictamine si la incorporación de la tecnología es considerada o no coste-efectiva. El ejemplo más conocido es el umbral que emplea el National Institute for Health and Care Excellence (NICE), establecido entre 20.000 a 30.000 libras por AVAC en Inglaterra (NICE, 2013). En España, la mención a la cifra de 30.000 euros por AV/AVAC se extendió tras la publicación de una revisión de la literatura que observó que, en la mayoría de ACE realizados en España, los autores concluían positivamente sobre el coste-efectividad de la tecnología evaluada cuando su coste por AV era inferior a este valor (Sacristán et al., 2002). Estas estimaciones no provienen de estudios empíricos y han sido criticadas por su arbitrariedad.

La falta de base teórica y científica en la fijación del umbral de coste-efectividad ha potenciado un aumento reciente en el número de estudios empíricos, y ha expuesto un desacuerdo notable en la literatura acerca de lo que el umbral debe representar (Vallejo-Torres et al., 2016). El valor umbral puede reflejar cuánto está dispuesto o cuánto es capaz de invertir el sistema por unidad de efectividad en salud ganada. Estos dos aspectos no necesariamente confluyen, por lo que se observan en la literatura dos corrientes conceptuales que enfatizan perspectivas diferentes: unos abogan por que el umbral refleje la valoración monetaria (o predisposición a pagar) de la sociedad por ganancias en salud (perspectiva de la demanda) y otros porque el umbral se base en el coste de oportunidad resultante de la desinversión requerida para generar recursos para una nueva tecnología (perspectiva de la oferta). La primera idea trata de incorporar las preferencias de la población en línea con el enfoque adoptado en otros ámbitos públicos donde se utiliza el análisis coste-beneficio para tomar decisiones de inversión, y considera que el umbral debe reflejar el valor de consumo que 
una sociedad otorga a las ganancias marginales en salud. La segunda está fundamentada en la consideración de las restricciones presupuestarias a las que se enfrentan los decisores y se basa en la idea de que, en un contexto donde el presupuesto ha sido previamente asignado, adoptar una nueva tecnología que impone costes adicionales al sistema de salud implica desinvertir en servicios existentes; lo que tendrá un efecto perjudicial en la salud de otras personas. Por lo tanto, de acuerdo con esta segunda perspectiva, el umbral debe representar el coste por AV/AVAC de los servicios que dejarán de financiarse, que idealmente y, siguiendo la lógica de las llamadas league tables, deberían ser aquellos servicios con el mayor coste por AVAC de los ya incluidos en la cartera. Esto permitiría evaluar si la mejora en salud que se espera obtener del uso de la nueva tecnología es superior a las pérdidas en salud que supondrá la desfinanciación de servicios actualmente prestados.

Ambas perspectivas ofrecen argumentos convincentes para su consideración en la estimación del valor umbral, y pese a que muchos autores tienden a defender una línea y oponerse a la otra, otros han recalcado la naturaleza complementaria de ambas (Baker et al., 2011) y reclaman información sobre cada uno de ellos (Brouwer et al., 2018). Sin embargo, a falta de un marco capaz de integrar las preferencias de la población y las restricciones presupuestarias a las que se enfrentan los decisores en la fijación de un umbral de coste-efectividad, estas dos visiones continúan tratándose como perspectivas alternativas.

Defensores del principio del coste de oportunidad han realizado un estudio pionero con el objetivo de estimar empíricamente el valor umbral para el NICE, concluyendo que esta cifra es cercana a 13.000 libras (Claxton et al., 2015), muy por debajo del rango actualmente empleado por esta institución. En España, la primera estimación realizada en este sentido estableció un valor de entre 22.000 y 25.000 euros (Vallejo-Torres, García-Lorenzo y Serrano-Aguilar 2018), también por debajo de la cifra de 30.000 euros referida en la literatura. Está por ver el efecto que esta evidencia científica ejerza en la toma de decisiones sanitarias, sobre todo en un contexto donde la autorización de la innovación sanitaria con una efectividad relativa muy reducida y costes (muy) elevados empuja a los financiadores a incluir en cartera medicamentos con una relación coste-efectividad muy por encima de los citados umbrales. Este hecho denota que, incluso cuando el criterio de coste-efectividad juega un papel en la toma de decisiones, este no es necesariamente el único factor que se considera y la aplicación del umbral no se realiza forzosamente de manera estricta. Un ejemplo de esto lo ofrece de nuevo el NICE, que emplea un umbral 2,5 veces mayor a su límite inferior, es decir, lo sitúa en 50.000 libras, para tratamientos que «alargan la vida al final de la vida». En España, la evidencia actual señalaría que una tecnología es coste-efectiva si su coste por AVAC es inferior a los 25.000 euros. Sin embargo, en casos donde se esté dispuesto a sacrificar eficiencia en aras de otros criterios, como la equidad, la regla del rescate, etc., tecnologías con un coste por AVAC superior podrían ser incluidas en la cartera de manera justificada. Para ello, sería imperativo definir los criterios explícitos y acomodarlos en un marco transparente y medible que valore aspectos más allá de la eficiencia, pero sin olvidarse de la 
misma. Asimismo, para abordar situaciones complejas en las decisiones de financiación y fijación de precio, cada vez se hace más necesario el uso de modelos basados en valor (value-based pricing) y sistemas de pago por resultados, que abordamos a continuación.

\section{El auge de los enfoques basados en el valor}

El término «basado en el valor» (value-based) es un concepto en auge, aunque difuso y sujeto a múltiples interpretaciones. Son muchas las críticas vertidas respecto a la falsa sinonimia entre valor y eficiencia (Reinhardt, 2016; Brownlee y Berman, 2016). Para algunos, el valor se define como los resultados alcanzados en salud (aquellos que realmente importan al paciente) por unidad monetaria invertida, siendo por tanto una medida de eficiencia en sí misma (Porter, 2010).

Como hemos comentado anteriormente, durante los últimos años, numerosos países desarrollados han abordado reformas para orientarse hacia una evaluación, regulación y financiación de las innovaciones farmacéuticas más basadas en su valor. Los esfuerzos se dirigen en primer término a introducir cambios para medir mejor el grado de innovación o el valor relativo que aportan los nuevos medicamentos, para posteriormente adecuar su financiación al mismo (Zozaya, et al., 2017; NICE 2017; Ognyanova, Zentner y Busse, 2011; Melck, 2016; AIFA, 2016; Rémuzat, Toumi y Falissard, 2013).

\subsection{Esquemas innovadores de cobertura y reembolso}

De la mano de los enfoques de financiación basados en el valor están surgiendo instrumentos innovadores de financiación, entre los que se encuentran los acuerdos de reembolso condicionado o los acuerdos de riesgo compartido. Estos esquemas pretenden ir más allá de los tradicionalmente empleados (descuentos lineales, a menudo confidenciales, techos de gasto o descuentos de precio por volumen de ventas).

Respecto a los acuerdos de riesgo compartido (ARC), en términos generales, se refieren a contratos entre el financiador sanitario y el fabricante, que pueden estar basados tanto en resultados financieros como en resultados clínicos o en salud, siendo estos últimos más interesantes desde el punto de vista del enfoque value-based. A medida que se genera mayor evidencia sobre la eficacia del tratamiento, a través del acuerdo puede decidirse si se continúa o se interrumpe la financiación, o bien condicionarse ya desde un primer momento a que los pacientes alcancen cierto nivel de respuesta clínica.

Los acuerdos basados en resultados clínicos tratan de paliar la incertidumbre sobre la efectividad real de los tratamientos (que normalmente discrepa de la eficacia observada en los ensayos clínicos, aplicados sobre una subpoblación específica) y sobre el gasto sanitario derivado de incorporar el nuevo tratamiento (que, a su vez 
dependerá, entre otros factores, de los patrones de prescripción, la demanda de los pacientes y las alternativas disponibles).

Desde la primera iniciativa «non cure, no pay», que tuvo lugar hace más de 20 años en Estados Unidos (Møldrup, 2005), son cada vez más los países del mundo desarrollado que se han embarcado en este tipo de acuerdos basados en resultados clínicos. Los primeros ejemplos incluyeron tratamientos para la esquizofrenia y las estatinas, fundamentalmente aplicados en los países anglosajones. La crisis económica de la década pasada potenció el interés de muchos otros países en estos acuerdos (Piatkiewicz, Traulsen y Holm-Larsen, 2018), que se han centrado especialmente en el ámbito de los medicamentos biológicos, las terapias dirigidas y las enfermedades infecciosas, raras o autoinmunes (Ferrario et al., 2017; Yu et al., 2017).

En la actualidad, muchos países utilizan, de un modo u otro, los ARC, siendo Italia, el Reino Unido, Alemania, Suecia, Estados Unidos y Australia los de mayor experiencia (Ferrario et al., 2017; WHO, 2015; Carlson, Chen y Garrison, 2017; Carlson et al., 2010). Por ejemplo, en Italia, el 58 por 100 de los 113 acuerdos de acceso gestionado en marcha se articularon en torno a los resultados clínicos alcanzados (AIFA, 2018). En España, desde 2011 se han realizado distintas experiencias piloto en Cataluña y Andalucía (Rojas García y Antoñanzas Villar, 2018; Abellán, Garrido y Martínez Pérez, 2013; Campillo-Artero y Kovacs, 2013).

Como potenciales virtudes de los ARC se puede mencionar que corresponsabilizan a los diferentes agentes del sistema, y pueden favorecer el acceso a la innovación y generar ahorros, redundando en una racionalización del gasto y mejora de la eficiencia (Piatkiewicz, Traulsen y Holm-Larsen 2018). Como contraparte, acarrean un notable coste de negociación, implementación y seguimiento, al menos a corto plazo. De hecho, en países como el Reino Unido, los conflictos de interés y las dificultades de implementación y evaluación de los ARC se hicieron patentes al desviar el foco desde este tipo de acuerdos a otros más simples (Scolding, 2010; Raftery, 2010). Actualmente, de los 177 acuerdos comerciales vigentes, el 72 por 100 son descuentos simples de precio y solo un 17 por 100 son acuerdos comerciales de acceso o esquemas de respuesta (NICE, 2018).

Entre los requisitos para que estos acuerdos de pago por resultados funcionen de acuerdo a lo previsto destaca la disponibilidad de sistemas de información adecuados e integrados, idealmente compatibles entre las distintas regiones. De hecho, una de las palancas del éxito en Italia fue la disponibilidad de registros de monitorización que permitían la evaluación continua de los fármacos en la práctica clínica real (Montilla et al., 2015). El éxito del acuerdo, y también uno de los mayores retos a lograr, recaerá en gran medida sobre el diseño contractual inicial. Entre los elementos críticos a considerar destacan la definición y seguimiento de las variables seleccionadas (subrogadas y finales), los procedimientos de obtención de evidencia, el plazo temporal y la gobernabilidad del acuerdo.

En el ámbito de la transparencia queda mucho camino por recorrer. La mayor parte de los resultados de los ARC nunca ve la luz pública. Solo recientemente han comenzado a publicarse algunos resultados cuantitativos de las experiencias 
realizadas (Piatkiewicz, Traulsen y Holm-Larsen 2018; Walzer, Droeschel y Shannon 2015; Clopes et al., 2017). Cabe señalar la importancia de evaluar los resultados del acuerdo tanto en términos de ahorros para el sistema como de acceso para los pacientes.

\subsection{La fijación de precios por indicación y para combinaciones de fármacos}

Otro de los retos que será necesario abordar en el medio plazo es el referido a la financiación de los fármacos con varias indicaciones y las combinaciones de fármacos (que, su vez, también pueden ser para más de una indicación).

Los medicamentos con indicaciones múltiples van en aumento: si en 2014, el 40 por 100 de los fármacos oncológicos contaba con varias indicaciones, se espera que en 2020 este porcentaje se incremente hasta el 67 por 100, y que casi la mitad de ellos cuente con tres indicaciones o más (IMS Institute, 2015).

La lógica de los precios multi-indicación radica en que, si la efectividad, y por tanto también el valor terapéutico y la relación coste-efectividad, de un fármaco difiere entre sus distintas indicaciones, ¿por qué fijar un precio único para todas las subpoblaciones? Un precio uniforme podría generar ineficiencias desde el punto de vista económico y de bienestar social. Si el precio se fija en base a la indicación de mayor valor, sería superior al óptimo para las indicaciones de menor valor, pudiendo provocar limitaciones de acceso. Si, por el contrario, el precio se guía por las indicaciones de menor valor, se desincentivaría la futura inversión y desarrollo del tratamiento en otras indicaciones (Mestre et al., 2015). Distintos trabajos han analizado, a través de ejemplos reales, cómo el valor de algunos tratamientos oncológicos difiere entre indicaciones, demostrando que en estos casos la fijación de un precio único impide capturar adecuadamente su valor en todas las indicaciones, y abogando por avanzar hacia una financiación por indicación (Mestre-Ferrándiz et al., 2018; Cole et al., 2018; Bach, 2014; Persson y Norlin, 2018).

Entre las barreras que dificultan la fijación de precios multi-indicación se encuentra su coste de implementación, ya que se necesita un considerable esfuerzo de gobernanza y disponer de sistemas de información adecuados. A esto se suman las posibles reticencias iniciales por parte de los distintos agentes del sistema. Por otro lado, no está claro el signo que puede acabar teniendo su efecto neto sobre el gasto (Mestre-Ferrándiz et al., 2018; Mestre et al., 2015).

Distintos países han acometido reformas para avanzar hacia un sistema de precios por indicación, algunos de una forma más explícita, como Bélgica, Alemania o Australia, y otros de facto, valiéndose de descuentos por indicación para lograr esa diferenciación de precio, como es el caso de Italia o el Reino Unido (Flume et al., 2016; Pearson, Dreitlein y Henshall, 2015; Mestre-Ferrándiz et al., 2018).

Por su parte, las combinaciones de fármacos también plantean un reto regulatorio relacionado con la fijación de precios diferenciales. La introducción de combinaciones en el mercado ha ido aumentando progresivamente, y se espera que continúe 
en el futuro gracias a la bioinformática, especialmente en oncología y hematología (Dry, Yang y Sáez-Rodríguez, 2016).

Se ha demostrado que aplicar de manera combinada algunos tratamientos potencia los resultados obtenidos cuando éstos se aplican por separado, de manera secuencial, gracias al efecto potenciador sobre las vías metabólicas o dianas terapéuticas (Zimmermann, Lehár y Keith, 2007; Ejim et al., 2011). Bajo la óptica del precio basado en valor, si el valor terapéutico añadido de una nueva combinación es mayor que el de las opciones terapéuticas disponibles (mayor eficacia, menor toxicidad, ambas, mejora de la adherencia), ésta podría aspirar a tener un precio mayor que ellas (Bulusu et al., 2016; Persson y Norlin, 2018).

En este sentido, durante todo el ciclo vital de las combinaciones (ya existen combinaciones autorizadas con más de una indicación), los precios deberían reflejar su valor terapéutico añadido y los mecanismos de su fijación, ser versátiles y dinámicos para responder a cambios periódicos, preservando los principios de eficiencia, equidad, sostenibilidad y solvencia del sistema, e incentivando al mismo tiempo la innovación.

En España, nuestro sistema no está todavía adaptado para capturar el valor terapéutico incremental de las nuevas combinaciones y poder responder de una forma dinámica a las frecuentes autorizaciones de nuevas indicaciones y restricciones o ampliaciones de las combinaciones existentes. El requisito necesario, pero no suficiente, para lograrlo es disponer de una infraestructura tecnológica adecuada, pero también se necesita trabajar en un sistema de precio y reembolso bien articulado con criterios específicos y explícitos, así como desarrollar una serie de incentivos que fomenten el uso de la información obtenida (Mestre-Ferrándiz et al., 2018).

\section{Conclusiones}

Las innovaciones farmacéuticas han ido creciendo en número, complejidad y coste, obligando a los sistemas sanitarios a adecuar sus sistemas regulatorios a estos nuevos medicamentos. Los modelos regulatorios están tratando de flexibilizarse y orientarse más hacia el valor de los nuevos medicamentos, implantando diversas alternativas de autorización, cobertura, fijación de precios y monitorización posautorización. No obstante, su grado de implantación es muy variable entre países y a menudo no logran sino aportar soluciones parciales a los problemas planteados.

El número de países que emplean la evaluación económica como cuarta barrera para decidir la cobertura pública de las innovaciones sanitarias va en aumento. Sin embargo, en España su papel sigue siendo bastante limitado, a pesar de las menciones que se han ido sucediendo en el ordenamiento jurídico. El estudio de la relación coste-efectividad sigue siendo opcional y los informes siguen sin ser de carácter vinculante, a pesar de los esfuerzos de las agencias de evaluación de tecnologías sanitarias. Esto nos aleja de la tónica de otros países de nuestro entorno, cada vez más centrados en aplicar sistemas basados en el valor, valiéndose de mecanismos 
más sofisticados como los acuerdos de reembolso condicionado o la financiación por indicaciones o para combinaciones de fármacos.

En el futuro, a medida que avance la medicina personalizada y la tecnología de la información permita identificar mejor la respuesta de los pacientes, el pago por resultados tendrá un obligado encaje en los sistemas sanitarios.

\section{Referencias bibliográficas}

[1] ABELLÁN, J. M.; GARRIDO, S. y MARTÍNEZ PÉREZ, J. E. (2013). Evidencia de los acuerdos de riesgo compartido como fórmula de cobertura de nuevas tecnologías sanitarias. Grupo de Investigación en Economía de la Salud y Evaluación Económica. Departamento de Economía Aplicada. Universidad de Murcia.

[2] AIFA (2016). «Criteri per la classificazione dei farmaci innovativi e dei farmaci oncologici innovativi». http://www.agenziafarmaco.gov.it/content/criteri-la-classificazione-dei-farmaci-innovativi-e-dei-farmaci-oncologici-innovativi-050420.

[3] AIFA (2018). «Comunicazioni Managed Entry Agreements (MEA). Agenzia Italiana del Farmaco». http://www.aifa.govit/content/comunicazioni-managed-entry-agreements-mea.

[4] ARROWSMITH, J. (2011). «Trial Watch: Phase III and Submission Failures: 20072010». Nature Reviews. Drug Discovery, 10 (2), 87.

[5] BACH, P. B. (2014). «Indication-Specific Pricing for Cancer Drugs». JAMA, 312 (16) (octubre 22). 1629-1630.

[6] BACH, P. B.; GIRALT, S. A. y SALTZ, L. B. (2017). «FDA Approval of Tisagenlecleucel: Promise and Complexities of a $\$ 475000$ Cancer Drug». JAMA, 318 (19), 18611862.

[7] BACKHOUSE, M. E., Michael Wonder, Edward Hornby, Anne Kilburg, Michael Drummond, y Friedrich Karl Mayer (2011), «Early Dialogue between the Developers of New Technologies and Pricing and Reimbursement Agencies: A Pilot Study», Value in Health: The Journal of the International Society for Pharmacoeconomics and Outcomes Research 14 (4) (junio): 608-615.

[8] BAIRD, L. G.; BANKEN, R.; EICHLER, H.-G.; KRISTENSEN, F. B.; LEE, D. K.; LIM, J. C. W.; LIM, R. et al. (2014). «Accelerated Access to Innovative Medicines for Patients in Need». Clinical Pharmacology and Therapeutics, 96 (5) (noviembre), 559-571.

[9] BAKER, R.; CHILTON, S.; DONALDSON, C.; JONES-LEE, M. E. L.; MASON, H.; METCALF, H.; PENNINGTON, M. y WILDMAN, J. (2011). «Searchers vs Surveyors in Estimating the Monetary Value of a QALY: Resolving a Nasty Dilemma for NICE». Health Economics, Policy and Law 6 (4) (octubre), 435-447.

[10] BARRATT, R. A.; BOWENS, S. L.; McCUNE, S. K.; JOHANNESSEN, J. N. y BUCKMAN, S. Y. (2012). «The Critical Path Initiative: Leveraging Collaborations to Enhance Regulatory Science». Clinical Pharmacology and Therapeutics, 91 (3) (marzo), 380383.

[11] BAUER, P. y KÖNIG, F. (2014). «The Risks of Methodology Aversion in Drug Regulation». Nature Reviews. Drug Discovery, 13 (5), 317-318.

[12] BORDEN, E. C. y DOWLATI, A. (2012). «Phase I Trials of Targeted Anticancer Drugs: A Need to Refocus». Nature Reviews. Drug Discovery, 11 (12) (diciembre), 889-890. 
[13] BOUVY, J. C.; EBBERS, H. C.; SCHELlEKENS, H. y KOOPMANSCHAP, M. A. (2013). «The Cost-Effectiveness of Periodic Safety Update Reports for Biologicals in Europe». Clinical Pharmacology and Therapeutics, 93 (5) (mayo), 433-442.

[14] BOUVY, J. C.; KOOPMANSCHAP, M. A.; SHAH, R. R. y SCHELLEKENS, H. (2012). «The Cost-Effectiveness of Drug Regulation: The Example of Thorough QT/ QTc Studies». Clinical Pharmacology and Therapeutics, 91 (2) (febrero), 281-288.

[15] BRECKENRIDGE, A.; FELDSCHREIBER, P.; GREGOR, S.; RAINE, J. y MULCAHY, L.-A. (2011). «Evolution of Regulatory Frameworks». Nature Reviews. Drug Discovery, 10 (1) (enero), 3-4.

[16] BROUWER, W.; VAN BAAL, P.; VAN EXEL, J. y VERSTEEGH, M. (2018). «When Is It Too Expensive? Cost-Effectiveness Thresholds and Health Care Decision-Making». The European Journal of Health Economics. HEPAC (Health Economics in Prevention and Care).

[17] BROWNLEE, S. y BERMAN, A. (2016). Defining Value in Health Care Resource Utilization: Articulating the Role of the Patient. The John A. Hartford Foundation.

[18] BULUSU, K. C.; GUHA, R.; MASON, D. J.; LEWIS, R. P. I.; MURATOV, E.; KALANTAR MOTAMEDI, Y.; COKOL, M. y BENDER, A. (2016). «Modelling of Compound Combination Effects and Applications to Efficacy and Toxicity: State-of-the-Art, Challenges and Perspectives». Drug Discovery Today, 21 (2), 225-238.

[19] CAMPILLO-ARTERO, C (2013). «A Full-Fledged Overhaul Is Needed for a Risk and Value-Based Regulation of Medical Devices in Europe». Health Policy (Amsterdam, Netherlands), 113 (1-2) (noviembre), 38-44.

[20] CAMPILLO-ARTERO, C (2015). «Nuevos medicamentos: ¿cuanto se innova?». Ges. Clín. Sanit., 58, 7-9.

[21] CAMPILLO-ARTERO, C (2016). «Reformas de la regulación de las tecnologías médicas y la función de los datos de la vida real». En Datos de la vida real en el sistema sanitario español. Fundación Gaspar Casal. Madrid.

[22] CAMPILLO-ARTERO, C. y JUAN E. (2014). «Regaining HTA from Oblivion: Improving and Integrating the Regulation of Drugs, Devices, Diagnostics and Surgical Innovations». En J. del Llano y C. Campillo-Artero (eds.), Health Technology Assessment and Health Policy Today: A Multifaceted View of Their Unstable Crossroads. Springer International Publishing.

[23] CAMPILLO-ARTERO, C. y M. KOVACS, F. (2013). «The Use of Risk Sharing Tools for Post Adoption Surveillance of a Non Pharmacological Technology in Routine Practice: Results after One Year». BMC Health Services Research, 13 (mayo 20), 181.

[24] CARLSON, J. J.; CHEN, S. y GARRISON, L.P. (2017). «Performance-Based Risk-Sharing Arrangements: An Updated International Review». PharmacoEconomics, 35 (10) (octubre 1), 1063-1072.

[25] CARLSON, J. J.; SULLIVAN, S. D.; GARRISON, L. P.; NEUMANN, P. J. y VEENSTRA, D. L. (2010). «Linking Payment to Health Outcomes: A Taxonomy and Examination of Performance-Based Reimbursement Schemes between Healthcare Payers and Manufacturers». Health Policy, 96 (3) (agosto), 179-190.

[26] CHANDRA, A.; GARTHWAITE, C. y STERN, A. D. (2017). «Characterizing the Drug Development Pipeline for Precision Medicines». NBER Working Paper. National Bureau of Economic Research. doi:10.3386/w24026. http://www.nber.org/papers/ w24026. 
[27] CLAXTON, K.; MARTIN, S.; SOARES, M.; RICE, N.; SPACKMAN, E.; HINDE, S.; DEVLIN, N.; SMITH, P. C. y SCULPHER, M. (2015). «Methods for the Estimation of the National Institute for Health and Care Excellence Cost-Effectiveness Threshold». Health Technology Assessment (Winchester, England), 19 (14) (febrero), 1-503, v-vi.

[28] CLOPES, A.; GASOL, M.; CAJAL, R.; SEGÚ, L.; CRESPO, R.; MORA, R. y SIMON, S. et al. (2017). «Financial Consequences of a Payment-by-Results Scheme in Catalonia: Gefitinib in Advanced EGFR-Mutation Positive Non-Small-Cell Lung Cancer». Journal of Medical Economics, 20 (1), 1-7.

[29] COLE, A.; TOWSE, A.; LORGELLY, P. y SULLIVAN, R (2018). «Economics of Innovative Payment Models Compared with Single Pricing of Pharmaceuticals». OHE Research Paper 18/04.

[30] COMISIÓN NACIONAL DE LOS MERCADOS Y LA COMPETENCIA (2015). «Proyecto de Real Decreto por el que se regula la financiación y fijación de precios de medicamentos y productos sanitarios y su inclusión en la prestación farmacéutica del Sistema Nacional de Salud. IPN/CNMC/023/15». https://www.cnmc.es/expedientes/ipncnmc02315.

[31] DANZON, P. M. (2018). «Differential Pricing of Pharmaceuticals: Theory, Evidence and Emerging Issues», PharmacoEconomics (julio 30). doi:10.1007/s40273-018-0696-4.

[32] DOLGIN, E. (2015). «Oncolytic Viruses Get a Boost with First FDA-Approval Recommendation». Nature Reviews. Drug Discovery, 14 (6) (junio), 369-371.

[33] DRUMMOND, M. F.; SCULPHER, M. J.; CLAXTON, K.; STODDART, G. L. y TORRANCE, G. W. (2015). Methods for the economic evaluation of health care programmes. Oxford University Press.

[34] DRY, J. R.; YANG, M. y SÁEZ-RODRÍGUEZ, J. (2016). «Looking beyond the cancer cell for effective drug combinations». Genome Medicine, 8 (1) (noviembre 25), 125. doi:10.1186/s13073-016-0379-8.

[35] ECKERMANN, S. y WILLAN, A. R. (2007). «Expected Value of Information and Decision Making in HTA». Health Economics, 16 (2) (febrero), 195-209.

[36] EICHLER, H.-G.; BLOECHL-DAUM, B.; ABADIE, E.; BARNETT, D.; KÖNIG, F. y PEARSON, S. (2010). «Relative Efficacy of Drugs: An Emerging Issue between Regulatory Agencies and Third-Party Payers». Nature Reviews. Drug Discovery, 9 (4), 277-291.

[37] EICHLER, H.-G.; BLOECHL-DAUM, B.; BRASSEUR, D.; BRECKENRIDGE, A.; LEUFKENS, H.; RAINE, J.; SALMONSON, T.; SCHNEIDER, C. K. y RASI, G. (2013). «The Risks of Risk Aversion in Drug Regulation». Nature Reviews. Drug Discovery, 12 (12), 907-916.

[38] EICHLER,H.-G.; PIGNATTI, F.; FLAMION,B.; LEUFKENS, H.y BRECKENRIDGE, A. (2008). «Balancing Early Market Access to New Drugs with the Need for Benefit/ Risk Data: A Mounting Dilemma». Nature Reviews. Drug Discovery, 7 (10), 818-826.

[39] EICHLER, H.-G.; THOMSON, A.; EICHLER, I. y SCHNEEWEISS, S. (2015). «Assessing the Relative Efficacy of New Drugs: An Emerging Opportunity». Nature Reviews. Drug Discovery, 14 (7), 443-444.

[40] EICHLER, H.-G.; BAIRD, L. G.; BARKER, R.; BLOECHL-DAUM, B.; BØRLUMKRISTENSEN, F.; BROWN, J. y CHUA et al., R. (2015). «From Adaptive Licensing to Adaptive Pathways: Delivering a Flexible Life-Span Approach to Bring New Drugs to Patients». Clinical Pharmacology and Therapeutics, 97 (3) (marzo), 234-246. 
[41] EICHLER, H.-G.; OYE, K.; BAIRD, L. G.; ABADIE, E.; BROWN, J.; DRUM, C. L. y FERGUSON, J. et al. (2012). «Adaptive Licensing: Taking the Next Step in the Evolution of Drug Approval». Clinical Pharmacology \& Therapeutics, 91 (3) (marzo), 426-437.

[42] EJIM, L.; FARHA, M. A.; FALCONER, S. B.; WILDENHAIN, J.; COOMBES, B. K.; TYERS, M.; BROWN, E. D. y WRIGHT, G. D. (2011). «Combinations of Antibiotics and Nonantibiotic Drugs Enhance Antimicrobial Efficacy». Nature Chemical Biology, 7 (6) (junio), 348-350.

[43] EMA(European Medicines Agency) (2016). «Final report on the adaptive pathways pilot». http://www.ema.europa.eu/ema/pages/includes/document/open_document.jsp?web ContentId=WC500211526.

[44] EMA (2014a). «Pilot project on adaptive licensing». EMA/254350/2012.

[45] EMA (2014b). «Adaptive Pathways to Patients: Report on the Initial Experience of the Pilot Project». EMA/758619/2014.

[46] EMA. «Benefit-Risk Methodology Project: Work Package 3 Report: Field Tests». EMA/718294/2011: 29.

[47] FERRARIO, A.; ARĀJA, D.; BOCHENEK, T.; ČATIĆ, T.; DANKÓ, D.; DIMITROVA, M. y FÜRST, J. et al. (2017). «The Implementation of Managed Entry Agreements in Central and Eastern Europe: Findings and Implications». Pharmacoeconomics, 35 (12), 1271-1285.

[48] FLUME, M.; BARDOU, M.; CAPRI, S.; SOLA-MORALES, O.; CUNNINGHAM, D.; LEVIN, L.-A. y TOUCHOT, N. (2016). «Feasibility and attractiveness of indication value-based pricing in key EU countries». Journal of Market Access \& Health Policy, 4. https://www.ncbi.nlm.nih.gov/pmc/articles/PMC4864834/.

[49] FORDA, S. R.; BERGSTRÖM, R.; CHLEBUS, M.; BARKER, R. y HØNGAARD ANDERSEN, P. (2013). «Priorities for Improving Drug Research, Development and Regulation». Nature Reviews. Drug Discovery 12 (4) (abril). 247-248.

[50] GASPAR, R.; AKSU, B.; CUINE, A.; DANHOF, M.; JADRIJEVIC-MLADAR TAKAC, M.; LINDEN, H. H. y LINK, A. et al. (2012). «Towards a European Strategy for Medicines Research (2014-2020): The EUFEPS Position Paper on Horizon 2020». European Journal of Pharmaceutical Sciences: Official Journal of the European Federation for Pharmaceutical Sciences, 47 (5) (diciembre 18), 979-987.

[51] GOLDMAN, M (2012). «The Innovative Medicines Initiative: A European Response to the Innovation Challenge». Clinical Pharmacology \& Therapeutics, 91 (3), 418-425.

[52] GOLDMAN, M.; SEIGNEURET, N. y EICHLER, H.-G. (2015). «The Innovative Medicines Initiative: An Engine for Regulatory Science». Nature Reviews. Drug Discovery, 14 (1), 1-2.

[53] VAN DER GRONDE, C. A.; UYL-DE GROOT, C. A. y PIETERS, T. (2017). «Addressing the Challenge of High-Priced Prescription Drugs in the Era of Precision Medicine: A Systematic Review of Drug Life Cycles, Therapeutic Drug Markets and Regulatory Frameworks». PLOS ONE 12 (8) (agosto 16), e0182613. Ed. Cathy Mihalopoulos.

[54] GUO, J. J.; PANDEY, S.; DOYLE, J.; BIAN, B.; LIS, Y. y RAISCH, D. W. (2010). «A Review of Quantitative Risk-Benefit Methodologies for Assessing Drug Safety and Efficacy-Report of the ISPOR Risk-Benefit Management Working Group». Value in Health: The Journal of the International Society for Pharmacoeconomics and Outcomes Research, 13 (5) (agosto), 657-666. 
[55] HOWARD, D. H. (2011). «Realigning Incentives for Developing and Pricing New Anticancer Treatments». JAMA, 305 (22) (junio 8), 2347-2348.

[56] HUNTER, N. L. y SHERMAN, R. E. (2017). «Combination Products: Modernizing the Regulatory Paradigm». Nature Reviews. Drug Discovery, 16 (8) (agosto), 513-514.

[57] HUSEREAU, D.; HENSHALL, C. y JIVRAJ, J. (2014). «Adaptive Approaches to Licensing, Health Technology Assessment, and Introduction of Drugs and Devices». International Journal of Technology Assessment in Health Care, 30 (3) (julio), 241-249.

[58] IMS Institute (2015). «Developments in Cancer Treatments, Market Dynamics, Patient Access and Value».http://keionline.org/sites/default/files/IIHI_Oncology_Trend_ Report_2015.pdf.

[59] INSTITUTE OF MEDICINE (2011). Building a National Framework for the Establishment of Regulatory Science for Drug Development: Workshop Summary. The National Academies Collection: Reports Funded by National Institutes of Health. Washington (DC). National Academies Press (US). http://www.ncbi.nlm.nih.gov/books/NBK54404/.

[60] INSTITUTE OF MEDICINE (2013). Implementing a National Cancer Clinical Trials System for the 21st Century: Second Workshop Summary. Washington, D.C., USA. National Academies Press. doi:10.17226/18362. https://www.nap.edu/read/18362/ chapter/2.

[61] KHOZIN, S.; LIU, K.; JAROW, J. P. y PAZDUR, R. (2015). «Regulatory Watch: Why Do Oncology Drugs Fail to Gain US Regulatory Approval?». Nature Reviews. Drug Discovery, 14 (7) (julio), 450-451.

[62] KIMMELMAN, J. (2015). «The Secret Realm of Phase I Trials in Healthy Volunteers». $B M J, 350$ (junio 26), h3444. Clinical Research Ed.

[63] KÖHLER, M.; HAAG, S.; BIESTER, B.; BROCKHAUS, A. C.; MCGAURAN, N.; GROUVEN, U. y KÖLSCH, H. et al. (2015). «Information on New Drugs at Market Entry: Retrospective Analysis of Health Technology Assessment Reports versus Regulatory Reports, Journal Publications, and Registry Reports». BMJ, 350 (febrero 26), h796, Clinical Research Ed.

[64] KOMAROVA, N. L. y BOLAND, C. R. (2013). «Cancer: Calculated Treatment». Nature, 499 (7458) (julio 18), 291-292.

[65] KUEHN, B. M. (2017). «The Promise and Challenges of CAR-T Gene Therapy». JAMA, 318 (22) (diciembre 12), 2167-2169.

[66] LANTHIER, M.; MILLER, K. L.; NARDINELLI, C. y WOODCOCK, J. (2013). «An Improved Approach to Measuring Drug Innovation Finds Steady Rates of First-in-Class Pharmaceuticals, 1987-2011». Health Affairs (Project Hope), 32 (8) (agosto), 14331439.

[67] LEMERY, S.; KEEGAN, P. y PAZDUR, R. (2017). «First FDA Approval Agnostic of Cancer Site-When a Biomarker Defines the Indication». The New England Journal of Medicine, 377 (15) (octubre 12), 1409-1412.

[68] LI, F.; ZHAO, C. y WANG, L. (2014). «Molecular-Targeted Agents Combination Therapy for Cancer: Developments and Potentials». International Journal of Cancer, 134 (6) (marzo 15), 1257-1269.

[69] MASSACHUSETTS INSTITUTE OF TECHNOLOGY (2010). “NEWDIGS”, New Drug Development ParadIGmS. Center for Biological Innovation, MIT.

[70] McKENNA, C. y CLAXTON, K. (2011). «Addressing Adoption and Research Design Decisions Simultaneously: The Role of Value of Sample Information Analysis». Me- 
dical Decision Making: An International Journal of the Society for Medical Decision Making, 31 (6) (diciembre), 853-865. doi:10.1177/0272989X11399921.

[71] MELCK, B. (2016). «Changes to AMNOG in the Pharmaceutical Care Strengthening Act. IHS Blogs». http://blog.ihs.com/changes-to-amnog-in-the-pharmaceutical-carestrengthening-act.

[72] MESSNER, D. A. y TUNIS, S. R. (2012). «Current and Future State of FDA-CMS Parallel Reviews». Clinical Pharmacology and Therapeutics, 91 (3) (marzo), 383385.

[73] MESSNER, D.A.; TOWSE, A.; MOHR, P. y GARAU, M. (2015). «The Future of Comparative Effectiveness and Relative Efficacy of Drugs: An International Perspective». Journal of Comparative Effectiveness Research, 4 (4) (agosto), 419-427.

[74] MESTRE, J.; TOWSE, A.; DELLAMANO, R. y PISTOLLATO, M. (2015). «Multi-indication Pricing: Pros, Cons and Applicability to the UK». Office of Health Economics. Seminar Briefing 56.

[75] MESTRE-FERRÁNDIZ; DEVERKA, P.; PISTOLlATO, M. y ROSENBERG, M. (2014). The Current Drug Development Paradigm: Responding to US and European Demands for Evidence of Comparative Effectiveness and Relative Effectiveness. Office of Health Economics. https://www.ohe.org/publications/current-drug-development-paradigm-responding-us-and-european-demands-evidence.

[76] MESTRE-FERRÁNDIZ, J.; ZOZAYA, N.; ALCALÁ, B. e HIDALGO-VEGA, A. (2018). «Multi-Indication Pricing: Nice in Theory but Can It Work in Practice?». PharmacoEconomics (septiembre 10). doi: 10.1007/s40273-018-0716-4.

[77] MILLER, K. L. y LANTHIER, M. (2015). «Regulatory Watch: Innovation in Biologic New Molecular Entities: 1986-2014». Nature Reviews. Drug Discovery, 14 (2) (febrero). 83. doi: $10.1038 / \mathrm{nrd} 4535$.

[78] MØLDRUP, C. (2005). «No cure, no pay». British Medical Journal, 330 (7502) (mayo 28), 1262-1264.

[79] MOLONEY, R.; MOHR, P.; HAWE, E.; SHAH, K.; GARAU, M. y TOWSE, A. (2015). «Payer Perspectives on Future Acceptability of Comparative Effectiveness and Relative Effectiveness Research». International Journal of Technology Assessment in Health Care, 31 (1-2) (enero), 90-98.

[80] MONTILlA, S.; XOXI, E.; RUSSO, P.; CICCHETTI, A. y PANI, L. (2015). «Monitoring Registries at Italian Medicines Agency: Fostering Access, Guaranteeing Sustainability». International Journal of Technology Assessment in Health Care 31 (04), 210-213. doi:10.1017/S0266462315000446.

[81] NATIONAL INSTITUTE FOR HEALTH CARE EXCELLENCE (NICE) (2013). «Guide to the Methods of Technology Appraisal». https://www.nice.org.uk/process/ pmg9/chapter/foreword.

[82] NEELAPU, S. S.; LOCKE, F. L.; BARTLETT, N. L.; LEKAKIS, L. J.; MIKLOS, D. B.; JACOBSON, C. A. y BRAUNSCHWEIG, I. et al. (2017). «Axicabtagene Ciloleucel CAR T-Cell Therapy in Refractory Large B-Cell Lymphoma». The New England Journal of Medicine 377 (26): 2531-2544. doi:10.1056/NEJMoa1707447.

[83] NEWTON, P. N.; SCHELLENBERG, D.; ASHLEY, E. A.; RAVINETTO, R.; GREEN, M. D.; TER KUILE, F. O.; TABERNERO, P.; WHITE, N. J. y GUERIN, P. J. (2015). «Quality Assurance of Drugs Used in Clinical Trials: Proposal for Adapting Guidelines». BMJ, 350 (febrero 25), h602. Clinical Research Ed. 
[84] NICE (2017). «Consultation on Changes to Technology Appraisals and Highly Specialised Technologies I NICE Technology Appraisal Guidance I NICE Guidance I Our Programmes I What We Do I About I NICE». CorporatePage. https://www.nice.org.uk/about/ what-we-do/our-programmes/nice-guidance/nice-technology-appraisal-guidance/consultation-on-changes-to-technology-appraisals-and-highly-specialised-technologies.

[85] NICE (2018). «List of Recommended Technologies That Include a Commercial Arrangement. Patient Access Schemes Liaison Unit». CorporatePage, NICE. https://www. nice.org.uk/about/what-we-do/patient-access-schemes-liaison-unit/list-of-technologies-with-approved-patient-access-schemes.

[86] OGNYANOVA, D.; ZENTNER, A. y BUSSE, R. (2011). «Pharmaceutical reform 2010 in Germany». Eurohealth, 17 (1), 11-13.

[87] PAPOIAN, T.; CHIU, H.-J., ELAYAN, I.; JAGADEESH, G.; KHAN, I.; LANIYONU, A. A.; LI, C. X.; SAULNIER, M.; SIMPSON, N. y YANG, B. (2015). «Secondary Pharmacology Data to Assess Potential Off-Target Activity of New Drugs: A Regulatory Perspective». Nature Reviews. Drug Discovery, 14 (4) (abril), 294. doi:10.1038/ nrd3845-c1.

[88] PEARSON, S. D.; DREITLEIN, B. y HENSHALL, C. (2015). «Indication-specific Princing in the United States Health Care System». Institute for Clinical and Economic Review. A Report from the 2015 ICER Membership Policy Summit.

[89] PERSSON, U. y NORLIN, J.M. (2018). «Multi-Indication and Combination Pricing and Reimbursement of Pharmaceuticals: Opportunities for Improved Health Care through Faster Uptake of New Innovations». Applied Health Economics and Health Policy (febrero 22), 1-9. doi:10.1007/s40258-018-0377-7.

[90] PIATKIEWICZ, T. J.; TRAULSEN, J. M. y HOLM-LARSEN, T. (2018). «Risk-Sharing Agreements in the EU: A Systematic Review of Major Trends». PharmacoEconomics-Open 2 (2) (junio), 109-123. doi:10.1007/s41669-017-0044-1.

[91] PORTER, M. E. (2010). «What Is Value in Health Care?» N-perspective. http://Dx.Doi. Org/10.1056/NEJMp1011024. doi:10.1056/NEJMp1011024.https://www.nejm.org/doi/ 10.1056/NEJMp1011024? url_ver=Z39.88-2003\&rfr_id=ori\%3Arid\%3Acrossref. org\&rfr_dat=cr_pub\%3Dwww.ncbi.nlm.nih.gov.

[92] PROWELL, T. M.; THEORET, M. R. y PAZDUR, R. (2016). «Seamless Oncology-Drug Development». The New England Journal of Medicine, 374 (21) (26), 2001-2003.

[93] PUTZEIST, M.; MANTEL-TEEUWISSE, A. K.; ARONSSON, B.; ROWLAND, M.; GISPEN-DE WIED, C. C.; VAMVAKAS, S.; HOES, A. W.; LEUFKENS, H. G. M. y EICHLER, H.-G. (2012). «Factors Influencing Non-Approval of New Drugs in Europe». Nature Reviews. Drug Discovery, 11 (12) (diciembre), 903-904.

[94] RAFTERY, J. (2010). «Costly failure of a risk sharing scheme». BMJ, 340.

[95] REEVES, B. C. (2014). «Reporting of Harms in Systematic Reviews and Their Primary Studies». BMJ, 349 (noviembre 21), g6819, Clinical Research Ed.

[96] REINHARDT, U. (2016). «Sense and nonsense in defining "value" in health care», presentado en National Institute of Health Care Management. Capitol Hill Briefing on The Future of Health Care in America.

[97] RÉMUZAT, C.; TOUMI, M. y FALISSARD, B. (2013). «New drug regulations in France: what are the impacts on market access? Part 1 - Overview of new drug regulations in France». Journal of Market Access \& Health Policy, 1 (0). http://www.jmahp.net/index. php/jmahp/article/view/20891. 
[98] ROBINSON, J. C. (2015). «Biomedical Innovation in the Era of Health Care Spending Constraints», Health Affairs (Project Hope) 34 (2) (febrero): 203-209.

[99] ROJAS GARCÍA, P. y ANTOÑANZAS VILLAR, F (2018). «Los contratos de riesgo compartido en el Sistema Nacional de Salud: percepciones de los profesionales sanitarios». Rev. Esp. Salud Pública, 92. http://www.mscbs.gob.es/biblioPublic/publicaciones/ recursos_propios/resp/revista_cdrom/VOL92/ORIGINALES/RS92C_201807041.pdf.

[100] ROSENBAUM, L. (2017). «Tragedy, Perseverance, and Chance-The Story of CAR-T Therapy». The New England Journal of Medicine, 377 (14) (octubre 5), 1313-1315.

[101] SACRISTÁN, J. A.; OLIVA, J.; DEL LLANO, J.; PRIETO, L. y PINTO, J. L. (2002). «¿Qué es una tecnología sanitaria eficiente en España?». Gaceta Sanitaria, 16 (4), 334-343.

[102] SAINI, P.; LOKE, Y. K.; GAMBLE, C.; ALTMAN, D. G.; WILLIAMSON, P. R. y KIRKHAM, J. J. (2014). «Selective Reporting Bias of Harm Outcomes within Studies: Findings from a Cohort of Systematic Reviews». BMJ, 349 (noviembre 21): g6501. Clinical Research Ed.

[103] SCHUSTER, S. J.; SVOBODA, J.; CHONG, E. A.; NASTA, S. D.; MATO, A. R.; ANAK, Ö. y BROGDON, J. L. et al. (2017). «Chimeric Antigen Receptor T Cells in Refractory B-Cell Lymphomas». The New England Journal of Medicine, 377 (26), 2545-2554.

[104] SCOLDING, N. (2010). «The multiple sclerosis risk sharing scheme». BMJ, 340 (c2882).

[105] SLEIJFER, S.; BOGAERTS, J. y SIU, L. L. (2013). «Designing Transformative Clinical Trials in the Cancer Genome Era». Journal of Clinical Oncology: Official Journal of the American Society of Clinical Oncology, 31 (15) (mayo 20): 1834-1841. doi:10.1200/JCO.2012.45.3639.

[106] TOPALIAN, S. L. (2017). «Targeting Immune Checkpoints in Cancer Therapy». JAMA, 318 (17) (noviembre 7), 1647-1648. doi:10.1001/jama.2017.14155.

[107] TOWSE, A.; COLE, A. y ZAMORA, B. (2018). The Debate on Indication Based Pricing in the U.S. and Five Major European Countries. OEH Consulting.

[108] TOWSE, A.; GARAU, M.; MOHR, P. y MESSNER, D. A. (2015). «Futurescapes: Expectations in Europe for Relative Effectiveness Evidence for Drugs in 2020». Journal of Comparative Effectiveness Research, 4 (4) (agosto), 401-418.

[109] TOWSE, A. y GARRISON, L. P. (2013). «Economic Incentives for Evidence Generation: Promoting an Efficient Path to Personalized Medicine». Value in Health: The Journal of the International Society for Pharmacoeconomics and Outcomes Research, 16 (6 Suppl) (octubre), S39-43. doi:10.1016/j.jval.2013.06.003.

[110] TOWSE, A.; OSSA, D.; VEENSTRA, D.; CARLSON, J. y GARRISON, L. (2013). «Understanding the Economic Value of Molecular Diagnostic Tests: Case Studies and Lessons Learned». Journal of Personalized Medicine, 3 (4) (octubre 25), 288-305.

[111] TRAN, E.; LONGO, D. L. y URBA, W, J. (2017). «A Milestone for CAR T Cells». The New England Journal of Medicine, 377 (26), 2593-2596.

[112] TRIBUNAL DE CUENTAS (2016). «Informe de fiscalización de la actividad económica desarrollada por el Ministerio de Sanidad, Servicios Sociales e Igualdad en relación con el área de farmacia, ejercicios 2014 y 2015. Informe 1185».www.tcu.es.

[113] TSOI, B.; MASUCCI, L.; CAMPBELL, K.; DRUMMOND, M.; O’REILLY, D. y GOEREE, R. (2013). «Harmonization of reimbursement and regulatory approval pro- 
cesses: a systematic review of international experiences». Expert Review of Pharmacoeconomics and Outcomes Research, 13 (4) (agosto 1), 497-511.

[114] VALLEJO-TORRES, L.; GARCÍA-LORENZO, B.; CASTILLA, I.; Valcárcel-Nazco, C.; GARCÍA-PÉREZ, L.; LINERTOVÁ, R.; POLENTINOS-CASTRO, E. y SERRANO-AGUILAR, P. (2016). «On the Estimation of the Cost-Effectiveness Threshold: Why, What, How?». Value in Health: The Journal of the International Society for Pharmacoeconomics and Outcomes Research, 19 (5) (agosto), 558-566.

[115] VALLEJO-TORRES, L.; GARCÍA-LORENZO, B. y SERRANO-AGUILAR, P. (2018). «Estimating a Cost-Effectiveness Threshold for the Spanish NHS». Health Economics, 27 (4) (abril), 746-761. doi:10.1002/hec.3633.

[116] VAN DEN BOGERT, C. A. y COHEN, A. F. (2015). «Need for a Proactive and Structured Approach to Risk Analysis When Designing Phase I Trials». BMJ, 351 (julio 22): h3899. Clinical Research Ed.

[117] WALZER, S.; DROESCHEL, D. y SHANNON, R. (2015). «Which Risk Share Agreements are Available and are Those Applied In Global Reimbursement Decisions?». Value in Health, 18 (7) (noviembre 1), A568. doi:10.1016/j.jval.2015.09.1869.

[118] WEBSTER, R. M. (2016). «Combination Therapies in Oncology». Nature Reviews. Drug Discovery, 15 (2) (febrero), 81-82. doi:10.1038/nrd.2016.3.

[119] WHO (2015). «Access to New Medicines in Europe: Technical Review of Policy Initiatives and Opportunities for Collaboration/Research». http://www.euro.who.int/data/assets/pdf_file/0003/273819/WHO-Medicines-Report-FINAL2015.pdf.

[120] WILLYARD, C. (2013). «"Basket Studies” Will Hold Intricate Data for Cancer Drug Approvals», Nature Medicine, 19 (6) (junio), 655. doi:10.1038/nm0613-655.

[121] WOODCOCK, J (2012). «Evidence vs. Access: Can Twenty-First-Century Drug Regulation Refine the Trade-Offs?». Clinical Pharmacology and Therapeutics, 91 (3) (marzo 1), 378-380. doi:10.1038/clpt.2011.337.

[122] WOODCOCK, J. y LAVANGE, L. M. (2017). «Master Protocols to Study Multiple Therapies, Multiple Diseases, or Both». The New England Journal of Medicine, 377 (1), 62-70. doi:10.1056/NEJMra1510062.

[123] YORDANOV, Y.; DECHARTRES, A.; PORCHER, R.; BOUTRON, I.; ALTMAN, D. G. y RAVAUD, P. (2015). «Avoidable Waste of Research Related to Inadequate Methods in Clinical Trials». BMJ, 350 (24): h809. Clinical Research Ed.

[124] YU, J. S.; CHIN, L.; OH, J. y FARIAS, J. (2017). «Performance-Based Risk-Sharing Arrangements for Pharmaceutical Products in the United States: A Systematic Review». Journal of Managed Care \& Specialty Pharmacy, 23 (10) (octubre), 10281040. doi:10.18553/jmcp.2017.23.10.1028.

[125] ZIMMERMANN, G. R.; LEHÁR, J. y KEITH, C. T. (2007). «Multi-Target Therapeutics: When the Whole Is Greater than the Sum of the Parts». Drug Discovery Today, 12 (1-2) (enero), 34-42. doi:10.1016/j.drudis.2006.11.008.

[126] ZOZAYA, N.; MARTÍNEZ-GALDEANO, L.; ALCALÁ, B. e HIDALGO, A. (2017). Evaluación, financiación y regulación de los medicamentos innovadores en la OCDE. Fundación Weber. http://weber.org.es. 